\title{
Evaluation of Functional Outcome Following Hybrid External Fixation in The Management of Schatzkers Type V and VI Tibial Plateau Fractures - A Prospective Study of 30 Patients
}

\author{
Subash Y, DNB Ortho \\ Department of Orthopaedics, Saveetha University Saveetha Medical College and Hospital, Chennai, India
}

\begin{abstract}
(c) (1)
This is an open-access article distributed under the terms of the Creative Commons Attribution License, which permits unrestricted use, distribution, and reproduction in any medium, provided the original work is properly cited
\end{abstract}

Date of submission: 04th April 2020

Date of acceptance: 01st February 2021

\begin{abstract}
Introduction: Fractures of the proximal tibia are high velocity injuries often associated with soft tissue compromise especially in the type V and VI fracture patterns. Dual plating is the preferred treatment option for these injuries but not in a setting where there is extensive soft tissue injury, as this can lead to problems with wound healing. The aim of this study was to evaluate the functional outcome following hybrid external fixation in the management of Schatzkers type V and VI fractures.

Materials and Methods: A total of 30 patients with type $\mathrm{V}$ and VI proximal tibial fractures who presented between January 2012 to January 2015 were managed with hybrid external fixation and were followed-up for a period of 3 years. Results: The mean age of the patients was 42.26 years with the left knee being more commonly affected. Schatzkers type $\mathrm{V}$ was the more common fracture type seen. The mean time to union was 12.06 weeks and the average range of motion achieved was 0 to $100^{\circ}$. The mean Rasmussens functional score was 25.4 at last follow-up and we had excellent results in 5 patients and good results in 22 patients.

Conclusion: Through this study, we conclude that the hybrid external fixation is an excellent option in the type $\mathrm{V}$ and VI fractures with extensive soft tissue compromise. It is easy to apply, facilitates early mobilisation of the joint and gives good functional results.
\end{abstract}

Keywords:

tibial plateau, schatzker, hybrid fixation, rasmussen

\section{INTRODUCTION}

Fractures of the proximal tibia are high velocity injuries which are quite difficult to manage due to the intraarticular nature of the fracture as well as depression and comminution seen in certain fracture patterns. They are often caused by injuries such as road traffic accidents and fall from height. In the elderly age group, they are usually caused by trivial injuries such as a slip and fall due to poor bone stock with advancing age ${ }^{1,2}$. They are brought about by a combination of axial loading with angular forces resulting in impaction and comminution of the anterior surface and the metaphysis. Schatzkers type one fractures are the most common type seen while type V and VI account for $15-30 \%$ of fractures ${ }^{3,4}$. These fractures are often associated with soft tissue compromise such as deep abrasions, compound injuries and blister formation due to extensive edema. They also have comminution at the fracture site along with ligamentous injuries, which lead to instability and are often difficult to manage. The management options available for these fractures are closed reduction and casting, unilateral external fixation, bicolumnar plating and the hybrid external fixation system. Closed reduction and casting is not advised in adults as it would be difficult to maintain reduction in a cast and could lead to complications such as malunion. This treatment option would also require a long period of immobilisation, which could end up in knee stiffness, and is only reserved in patients who are medically unfit for any surgical procedure. A unilateral external fixator is ideally used for temporary immobilisation of the fracture and in compound injuries till the condition of the soft tissues improve to facilitate a definitive internal fixation of the fracture. A longer period of immobilisation with a knee spanning external fixator can cause problems such as knee stiffness with decreased range of motion of the affected knee. The ideal treatment option would be the dual plating either through a midline incision or through two separate incisions. This option, however, requires extensive dissection leading to problems with wound healing related to decreased vascularity such as skin and muscle necrosis, as well as having increased risk of infection $^{5,6,7,8}$.

Corresponding Author: Yeshwanth Subash, Department of Orthopaedics, Saveetha Medical College, Saveetha Nagar, Thandalam, Chennai, Tamil Nadu, 602 105, India

Email: djyesh@rediffmail.com 
The hybrid external fixator combines an Ilizarov ring with a standard AO frame and can be used in compound injuries as well as in fractures with extensive soft tissue compromise as a definitive fixation option. The fixator acts on the principle of ligamentotaxis to reduce the fracture and to maintain the reduction as well. It provides a stable and definitive fixation and since it does not span the joint, the knee can be actively mobilised from day one to bring about a good range of motion of the knee joint and to promote cartilage regeneration and remodeling. In cases of fractures with impaction, small incisions can be made to elevate them and the fixation can also be supplemented with $\mathrm{K}$ wires, cannulated cancellous screws, or mini plates. Early weight bearing in a few weeks after the fracture starts consolidating can also be done with the hybrid fixator. The aim of this study was to evaluate the role of the hybrid external fixator in the management of Schatzkers type V and VI fractures, and to assess the functional and radiological outcomes using Rasmussens grading system.

\section{MATERIAL AND METHOD}

A total of 30 patients with Schatzkers type V and VI tibial plateau fractures who presented between January 2012 to January 2015 were treated with the hybrid external fixator and were followed-up for a period of 3 years. This study was undertaken after obtaining approval from the ethical committee of our institution. All skeletally mature patients with Schatzkers type V and VI fractures willing for surgery and follow-up were included in our study while Schatzkers types one to four fractures, patients with ipsilateral lower limb fractures, floating knee and patients with neurovascular injury were excluded. At the time of admission, all patients were assessed clinically and radiologically. At first examination, the neurovascular status was first assessed and documented. The extent of soft tissue compromise was noted and documented as well. In patients with gross swelling of the knee, ice pack application and limb elevation with either pillows or a Bohler braun splint was done immediately. The patients were then subjected to radiographs of the affected knee with the leg, which included AP, lateral as well as oblique views. In cases of fractures with extensive communition, CT scans were taken for pre-operative planning for surgery. All fractures were classified by the Schatzkers classification and the fracture type was documented in the case records.

Routine blood investigations were then sent for and the patients were worked up for the surgical procedure after obtaining the necessary medical and anaesthetic clearance. The patients were then taken up for surgery after obtaining proper informed and written consent. The procedures were performed under spinal anaesthesia under fluoroscopic guidance. Intravenous cephazolin was given at the time of induction of anaesthesia and was continued for three days post-operatively. The fractures were assessed under fluoroscopic guidance and initially traction was given to restore length, followed by a valgus or a varus stress based on the fracture pattern and displacement. In a few cases $2 \mathrm{~mm}$ $\mathrm{K}$ wires were used for the provisional fracture fixation especially in communited fracture patterns. Then a $1.8 \mathrm{~mm}$ wire was passed from lateral to the medial aspect at a distance of $15 \mathrm{~mm}$ from the joint surface to prevent septic arthritis from occurring. The wire was then tensioned in the standard manner and a 5/8th ring was attached to it. The second wire was passed from an anterolateral to posteromedial direction and care was taken to ensure that there was a throw of at least $60^{\circ}$ from the first wire to provide a stable construct followed by tensioning of the wire. Two $5 \mathrm{~mm}$ Schantz pins were then placed on the anteromedial border of the tibia and the Ilizarov ring and the Schantz pins were then connected with $250 \mathrm{~mm}$ tubular rods and universal clamps using a hybrid clamp. Final fracture reduction was checked in both AP and lateral views and confirmed to be anatomic. In three of our patients, there was depression in the lateral condyle, hence a mini incision was made over the anterior aspect of tibia and the fragment was elevated with a bone tap and fixed with a $\mathrm{K}$ wire. None of the cases needed supplementation with either cancellous screws or mini plates in our series. Bone grafting consent was taken from the patients prior to the surgical procedure but it was not performed as there were no large bone defects which needed grafting.

Out of the 30 patients in our study, 8 were operated on the first day and the remaining were operated on the 2 nd or $3 \mathrm{rd}$ day. Twenty-three fractures in our series were closed injuries with 11 of them were associated with significant soft tissue damage and blister formation. The blisters were either punctured or aspirated, ice compression and limb elevation was given, and the patients were taken up for surgery on day 2 or 3 . Seven patients had Gustillo and Anderson grade 2 and 3 compound injuries for which wound debridement was done followed by the hybrid external fixator application. Two patients had a grade 3 compound injury while five patients had a grade 2 injury. Out of the seven compound fractures, four were Schatztkers type VI and three were type V. The wound was primarily sutured in six patients while one patient with a grade $3 \mathrm{~B}$ compound fracture required a flap cover. Post-operatively all patients were made to sit up in bed on the same day of surgery and the knee and ankle were actively mobilised. Patients were then started on quadriceps exercises. They were mobilised on the 1st post-operative day with non-weight bearing walking with either a crutch or a walking frame support. Intravenous antibiotics were continued for three days post-operatively. Wound inspections in cases where mini incisions were made was done on the 3rd and 5 th postop day and sutures were removed on the 12th day.

The patients were taught how to clean the pin tracts themselves and were asked to do it daily. Post-operative 
Table I: Patient demographics and data

\begin{tabular}{|c|c|c|c|c|c|c|c|c|c|}
\hline $\begin{array}{l}\text { S. } \\
\text { No }\end{array}$ & Age & Sex & Side & $\begin{array}{c}\text { Fracture } \\
\text { classification }\end{array}$ & $\begin{array}{c}\text { Fracture } \\
\text { type }\end{array}$ & $\begin{array}{l}\text { Mode of } \\
\text { injury }\end{array}$ & $\begin{array}{c}\text { Surgical } \\
\text { time } \\
\text { (minutes) }\end{array}$ & $\begin{array}{c}\text { Time to } \\
\text { union } \\
\text { (weeks) }\end{array}$ & $\begin{array}{c}\text { Rasmussens } \\
\text { score }\end{array}$ \\
\hline 1 & 45 & $M$ & $\mathrm{R}$ & Type V & Closed & RTA & 45 & 11 & 29 \\
\hline 2 & 34 & $M$ & L & Type V & Closed & RTA & 50 & 12 & 22 \\
\hline 3 & 50 & $\mathrm{~F}$ & L & Type V & Closed & RTA & 43 & 13 & 24 \\
\hline 4 & 48 & $M$ & $\mathrm{R}$ & Type VI & Compound & RTA & 54 & 10 & 27 \\
\hline 5 & 24 & $\mathrm{~F}$ & $\mathrm{R}$ & Type V & Closed & $\mathrm{FFH}$ & 60 & 11 & 29 \\
\hline 6 & 60 & $\mathrm{~F}$ & L & Type VI & Closed & RTA & 48 & 12 & 25 \\
\hline 7 & 54 & $M$ & L & Type VI & Closed & RTA & 51 & 10 & 25 \\
\hline 8 & 38 & $M$ & $\mathrm{R}$ & Type V & Compound & RTA & 54 & 10 & 21 \\
\hline 9 & 49 & $M$ & $\mathrm{R}$ & Type V & Closed & $\mathrm{FFH}$ & 55 & 11 & 24 \\
\hline 10 & 50 & $\mathrm{~F}$ & $\mathrm{R}$ & Type V & Closed & RTA & 42 & 12 & 29 \\
\hline 11 & 29 & $M$ & $\mathrm{R}$ & Type V & Closed & RTA & 44 & 14 & 24 \\
\hline 12 & 26 & $\mathrm{~F}$ & $\mathrm{R}$ & Type V & Closed & RTA & 45 & 13 & 26 \\
\hline 13 & 34 & $\mathrm{~F}$ & L & Type VI & Compound & RTA & 41 & 14 & 25 \\
\hline 14 & 38 & $M$ & L & Type V & Closed & RTA & 52 & 11 & 26 \\
\hline 15 & 51 & $\mathrm{~F}$ & $\mathrm{R}$ & Type V & Closed & RTA & 60 & 14 & 28 \\
\hline 16 & 59 & $M$ & L & Type V & Closed & RTA & 54 & 13 & 25 \\
\hline 17 & 42 & $M$ & L & Type V & Closed & RTA & 56 & 14 & 25 \\
\hline 18 & 47 & $M$ & L & Type VI & Compound & $\mathrm{FFH}$ & 42 & 15 & 26 \\
\hline 19 & 54 & $M$ & $\mathrm{R}$ & Type V & Closed & RTA & 49 & 12 & 30 \\
\hline 20 & 40 & $\mathrm{~F}$ & $\mathrm{R}$ & Type VI & Compound & RTA & 50 & 12 & 26 \\
\hline 21 & 49 & $M$ & $\mathrm{R}$ & Type V & Closed & RTA & 45 & 11 & 24 \\
\hline 22 & 32 & $M$ & L & Type VI & Closed & RTA & 54 & 12 & 26 \\
\hline 23 & 24 & $M$ & $\mathrm{R}$ & Type VI & Closed & RTA & 60 & 13 & 24 \\
\hline 24 & 31 & $M$ & L & Type V & Compound & RTA & 62 & 14 & 21 \\
\hline 25 & 40 & $M$ & L & Type V & Closed & $\mathrm{FFH}$ & 58 & 12 & 25 \\
\hline 26 & 50 & $\mathrm{~F}$ & L & Type V & Closed & RTA & 59 & 11 & 26 \\
\hline 27 & 54 & $M$ & $\mathrm{R}$ & Type V & Closed & $\mathrm{FFH}$ & 60 & 11 & 25 \\
\hline 28 & 38 & $\mathrm{~F}$ & $\mathrm{R}$ & Type V & Compound & RTA & 54 & 12 & 26 \\
\hline 29 & 27 & $M$ & $\mathrm{R}$ & Type VI & Closed & RTA & 48 & 11 & 25 \\
\hline 30 & 51 & $M$ & $\mathrm{R}$ & Type VI & Closed & RTA & 45 & 12 & 24 \\
\hline
\end{tabular}

Abbreviations: M: Male, F: Female, L: Left, R: Right, RTA: Road traffic accidents, FFH: Fall from height.

Table II: Rasmussens functional grading

\begin{tabular}{|lccc|}
\hline S. No & Functional grading & No of patients & Percentage \\
\hline 1 & Excellent & 5 & 16.66 \\
2 & Good & 22 & 73.3 \\
3 & Fair & 3 & 10 \\
4 & Poor & 0 & 0 \\
\hline
\end{tabular}

Table III: Rasmussens radiological grading

\begin{tabular}{|lccc|}
\hline S. No & Radiological grading & No of patients & Percentage \\
\hline 1 & Excellent & 4 & 13.33 \\
2 & Good & 23 & 76.66 \\
3 & Fair & 3 & 10 \\
4 & Poor & 0 & 0 \\
\hline
\end{tabular}

radiographs were taken to assess the quality of reduction and restoration of the joint line. The patients were then discharged and were asked to review at one, three and six months and at yearly intervals thereafter where serial radiographs were taken and the progression of union was noted. Functional and radiological assessment was done using the Rasmussens scoring system and the data obtained were documented in the case records ${ }^{9}$. Clinical evidence of fracture union was taken to be lack of tenderness at the fracture site and absence of pain on weight bearing while radiologically it was bridging of at least three cortices in AP and lateral projection radiographs (Fig. 1,2). The hybrid fixator was removed after union at the fracture site which was at an average of 12.06 weeks. Associated ligamentous 

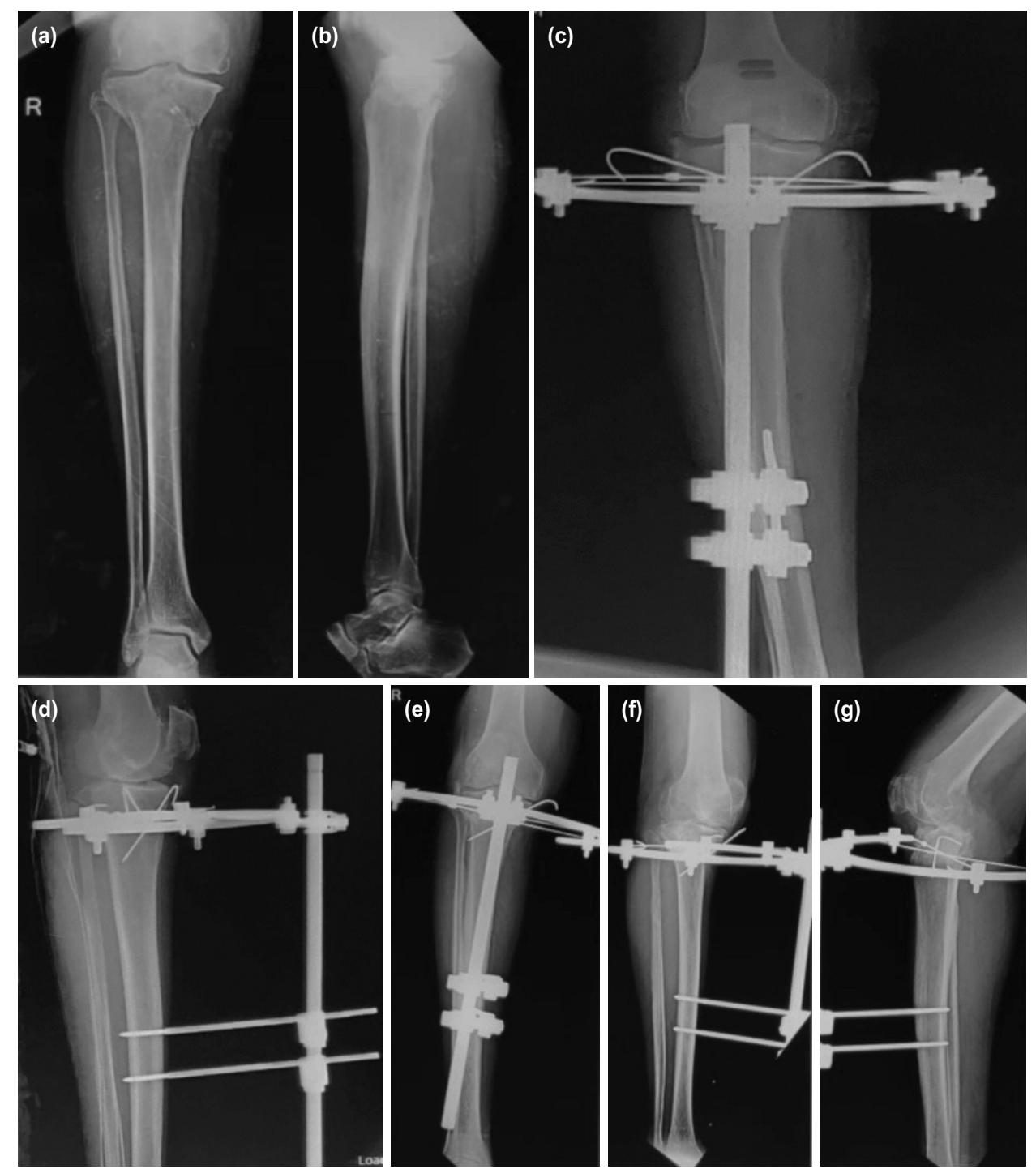

Fig. 1: (a,b) Showing the pre-operative radiograph. (c) Showing the immediate post-operative radiograph AP view. (d) Showing the immediate post-operative lateral radiograph. $(e, f, g)$ Showing complete union at the fracture site at three months follow-up.
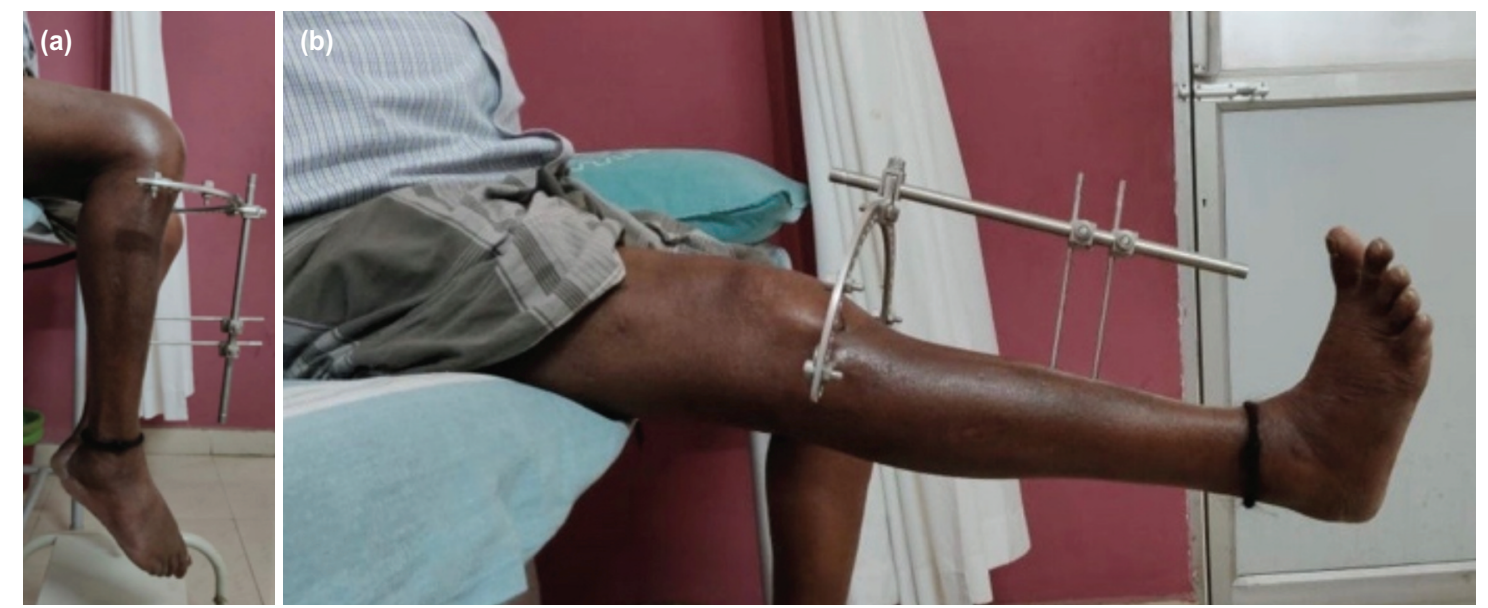

Fig. 2: (a) Showing good range of knee flexion. (b) Showing complete extension at the knee joint. 
injuries were not addressed primarily and were dealt with after union of the tibial plateau fractures. Three patients had collateral ligament injuries while one patient had an isolated anterior cruciate ligament and four patients had multiple ligamentous injuries which were addressed accordingly after fracture union. The data collected was analysed using IBM SPSS Version 22.0. [Armonk, NY: IBM Corp]. Chi square test was used in the comparison of categorical variables. A P value of less than 0.05 was considered to be statistically significant.

\section{RESULTS}

Mean age of the patients was 42.26 years ranging from 24 to 59 years. There was a male preponderance seen in our study with the left side being more commonly affected. Schatzkers type $\mathrm{V}$ was the most common type seen accounting for 19 cases (Table I). The time from presentation to surgery ranged from one to three days. The mean operative time was 51.33 minutes, ranging from 41 to 62 minutes. The average time to weight bearing was 8 weeks, ranging from 6 to 10 weeks. The mean duration of stay in the hospital was 12 days, ranging from 10 to 18 days. The mean time to fracture union was 12.06 weeks, ranging from 10 to 15 weeks. The average range of motion of knee achieved was 0 to $100^{\circ}$ with one patient having an extensor lag of $10^{\circ}$ and the average ankle range of motion was 0 to $20^{\circ}$ dorsiflexion and 0 to $35^{\circ}$ plantar flexion. The mean Rasmussens functional score at the time of the last follow-up was 25.4, ranging from 21 to 29 (Table II). According to Rasmussens functional grading we had excellent results in 5 patients, good results in 22, fair in 3 patients with no poor results seen. According to the radiological grading we had excellent results in 4 patients, good in 4 and fair in 3 patients with no poor results (Table III).

We had minor complication such as pin tract infection in four patients and superficial infection in two patients which settled down with a course of antibiotics. There were no major complications such as delayed union, nonunion, malunion, deep infection, nerve injury, fracture collapse or wire breakage seen in our study. All patients were satisfied with the functional outcome achieved. None of our patients were lost to follow-up.

\section{DISCUSSION}

Fractures of the proximal tibia are high velocity injuries which are quite difficult to manage. They are often caused by injuries such as road traffic accidents and fall from height. In the elderly age group, they are usually caused by trivial injuries such as a slip and fall due to poor bone stock with advancing age. Schatzkers type V and VI fractures are the most difficult to treat because they are usually associated with considerable soft tissue compromise in the form of compound injuries, deep abrasions, and blister formation. Factors such as communition at the fracture site, varus or valgus displacement, articular depression and associated ligamentous injury with instability further complicate the management. The principles of management in these fractures would be good anatomic reduction, elevation of depressed fragments to restore the integrity of the articular surface, avoidance of valgus or varus angulation, proper soft tissue handling, early mobilisation of the knee to promote a good range of motion and supervised weight bearing ${ }^{10,11}$.

The management options available for these fractures are closed reduction and casting, unilateral external fixation, bicolumnar plating and the hybrid external fixation system. Closed reduction and casting is not advised and is only reserved in patients who are medically unfit for any surgical procedure. A unilateral external fixator is ideally used for temporary immobilisation of the fracture and in compound injuries till the condition of the soft tissues improve to facilitate a definitive internal fixation of the fracture. A longer period of immobilisation with a knee spanning external fixator can cause problems such as knee stiffness with decrease range of motion of the affected knee.

Current literature proposes that the ideal treatment option would be dual plating either through a midline incision or through two separate incisions. This option, however, requires extensive dissection leading to problems with wound healing related to decreased vascularity such as skin and muscle necrosis, increased operative times and as well as having increased risk of infection. These complications can also be encountered even if these fractures are taken up for surgery after a delayed period once the soft tissue status of the limb is in an acceptable condition. The hybrid external fixator eliminates the delay for surgery and hence avoids complications such as knee stiffness, which are quite commonly seen in intra and periarticular fractures of the knee. It is minimally invasive, does not cause problems with soft tissue healing, requires shorter operative times, and is also cost effective to the patient. The hybrid external fixator combines an ilizarov ring with a standard AO frame and can be used as a definitive fixation option in compound injuries as well as in fractures with extensive soft tissue compromise $^{12,13}$.

The fixator acts on the principle of ligamentotaxis to reduce the fracture and to maintain the reduction as well. In bicondylar fractures, the separated or displaced condyles could be compressed with olive wires to provide a stable fixation. In cases of fractures with depression, a mini incision can be made to elevate the depressed fragments without any compromise to the soft tissues. The soft tissue handling is good, there is no blood loss, the fracture haematoma is not disturbed leading to better rates of union and the knee can be mobilised from day one resulting in a good range of motion with a better functional outcome. The 
fixator is as biomechanically stable as dual column plating $^{14,15,16}$.

The potential disadvantages possible with the hybrid fixator are wire breakage, valgus or varus collapse, pin tract sepsis, septic arthritis if the wires are places within the joint in the capsular reflection less than $10 \mathrm{~mm}$ from the joint line and common peroneal nerve injury if the wires are passed close to the fibular head. We did not encounter any of these complications in our study. In Aggarwal et al study of 56 patients they reported union time of 20.5 weeks with excellent results in 30 patients. They had complications such as osteomyelitis in three patients and pin tract infections in five patients ${ }^{17}$. In Venkatesh $\mathrm{G}$ et al study of 48 patients the mean union time was 13.3 weeks with 2 cases of delayed union seen. They had excellent results in 8 patients and good results in 30 patients ${ }^{18}$. Savolainan et al studied 33 patients and reported a union time of 20 weeks and had complications such as pin tract infection in 7 patients and septic arthritis in 1 patient $^{19}$.

In our study, we only had minor complications such as pin tract infection and superficial skin infections. We had excellent results in 5 patients, good in 22 and fair in 3 patients with no poor results seen. All our patients were happy with the procedure and the final functional outcome. None of our patients were lost to follow-up. We thereby conclude by stating that the hybrid external fixation system is an excellent treatment option in Schatzkers type V and VI fractures associated with soft tissue compromise and gives good functional results.

\section{CONCLUSION}

The hybrid external fixator combines an Ilizarov ring with a standard AO frame and can be used as a definitive fixation option in compound injuries as well as in fractures with extensive soft tissue compromise. The fixator acts on the principle of ligamentotaxis to reduce the fracture and to maintain the reduction as well. The fixator is as biomechanically stable as dual column plating. The soft tissue handling is good, there is no blood loss, the fracture haematoma is not disturbed leading to better rates of union and the knee can be mobilised from day one resulting in a good range of motion with a better functional outcome.

\section{CONFLICT OF INTEREST}

The authors declare no potential conflict of interest.

\section{REFERENCES}

1. Schatzker J. Fractures of the tibial plateau. In: Schatzker J, Tile M, editors. The Rationale of Operative Orthopaedic Care. Berlin: Springer-Verlag; 1987. p 279-95.

2. Burri C, Bartzke G, Coldewey J, Muggler E. Fractures of the tibial plateau. Clin Orthop Relat Res. 1979; (138): 84-93.

3. Hohl M. Tibial condylar fractures. J Bone Joint Surg Am. 1967; 49(7): 1455-67.

4. Roberts JM. Fractures of the condyles of the tibia. An anatomical and clinical end-result study of one hundred cases. J Bone Joint Surg Am. 1968; 50(8): 1505-21.

5. Moore TM, Patzakis MJ, Harvey JP. Tibial plateau fractures: definition, demographics, treatment rationale, and long results of closed traction management or operative reduction. J Orthop Trauma.1987; 1(2): 97-119.

6. Young MJ, Barrack RL. Complications of internal fixation of tibial plateau fractures. Orthop Rev. 1994; 23(2): 149-54.

7. Oestern HJ, Tscherne H, Pathophysiology and Classification of Soft Tissue Injuries Associated with Fractures. In: Tscherne H, Gotzen L, editors. Fractures with Soft Tissue Injuries. Berlin: Springer-Verlag; 1984. p 1-9.

8. Barei DP, Nork SE, Mills WJ, Henley MB, Benirschke SK. Complications associated with internal fixation of high-energy bicondylar tibial plateau fractures utilizing a two-incision technique. J Orthop Trauma. 2004; 18(10): 649-57. doi: 10.1097/00005131-200411000-00001

9. Knee Function-Rasmussen. J Orthop Trauma. 2006;20(8):S88

10. Mallik AR, Coval DJ, Whitelaw GP. Internal versus external fixation of bicondylar tibial plateau fractures. Orthop Rev. 1992; 21(12): 1433-6.

11. Kumar A, Whittle AP. Treatment of complex (Schatzker type VI) fractures of the tibial plateau with circular wire external fixation: retrospective case review. J Orthop Trauma. 2000; 14(5): 339-44. doi: 10.1097/00005131-200006000-00006

12. Buckle R, Blake R, Watson JT, Morandi M, Browner BD. Treatment of complex tibial plateau fractures with the Ilizarov external fixator. J Orthop Trauma. 1993; 7(2): 167. 
13. Zecher SB, Danziger MB, Segal D, Foster T, Whitelaw GP, Covall DJ. Treatment of high energy proximal tibial fractures using the Monticelli-Spinelli external fixator: a preliminary report. Am J Orthop (Belle Mead NJ). 1996; 25(1): 49-54.

14. Mikulak SA, Gold SM, Zinar DM. Small wire external fixation of high energy tibial plateau fractures. Clin Orthop Relat Res. 1998;(356):230-8. doi: 10.1097/00003086-199811000-00031

15. Yang M, Nayagam S, Saleh M. Stiffness Characteristics and interfragmentary displacement with different hybrid external fixators. Clin Biomech (Bristol, Avon). 2003; 18(2): 166-72. doi: 10.1016/s0268-0033(02)00175-4

16. Piper KJ, Won HY, Ellis AM. Hybrid external fixation in complex tibial plateau and plafond fractures: an Australian audit of outcome. Injury. 2005; 36(1): 178-84. doi: 10.1016/j.injury.2004.04.006

17. Aggarwal AK, Nagi ON. Hybrid External Fixation in Periarticular Tibial Fractures. Good Final Outcome in 56 Patients. Acta Orthop Belg. 2006; 72(4): 434-40.

18. Gupta SKV, Sunil G. Management of Tibial Metaphyseal Fractures by Hybrid External Fixator. Open J Orthop. 2014; 4(3): 849. doi: 10.4236/ojo.2014.43014

19. Savolainen VT, Pajarinen J, Hirvensalo E, Lindahl J. Hybrid external fixation in treatment of proximal tibial fractures: a good outcome in AO/ASIF type-C fractures. Arch Orthop Trauma Surg. 2010; 130(7): 897-901. doi: 10.1007/s00402-009-0931-8 